\title{
The effect of nano-additives on the processes of electrodeposition of nickel precipitation
}

\author{
Liudmila Degtyar ${ }^{1, *}$, Irina Zhukova $^{1}$, Vladimir Mishurov ${ }^{1}$, Elena Shubina ${ }^{1}$, and Valeria \\ Kovko $^{1}$ \\ ${ }^{1}$ Don State Technical University, 1, Gagarin square, 344003, Rostov-on-Don, Russia
}

\begin{abstract}
The article presents the results of investigates of the effect of ultrafine additives (zirconium diboride, silicon carbide, diamond) on the physical and mechanical properties of composite electrochemical nickel deposits obtained from colloid-electrolyte baths. It was revealed that the most effective nanostructured additives are zirconium diboride and ultrafine diamond. Current efficiency and potentiostatic researches shew mutual participation of finely dispersed nickel hydroxide compounds in the formation of a composite electrochemical deposits and dispersed phase of zirconium diboride or ultrafine diamond that are attendant in the solution or formed during electrolysis and introduced into the electrolyte. It is shown that the optimal values of internal tensions and microhardness are associated with the hardening of the nickel matrix together with various nano-dispersed additives that are included in the deposit. These deposits can be used as an alternative to chrome deposits on parts of machinery.
\end{abstract}

\section{Introduction}

The development of energy and resource-saving, environmentally accedtable and heavy-duty technologies is the main task of modern galvanic production. The development of new types of galvanic deposits with increased hardness, wear and corrosion resistance and other exploitative properties has great importance. The most commonly used protective deposit in industry is nickel. There are following directions of obtaining deposits containing a dispersed phase: deposits from suspension electrolytes obtained by the electrochemical method and containing the dispersed phase artificially introduced into the electrolyte; electrochemical deposits of electrolytes forming a dispersed phase during its preparation or electrolysis (also named colloid electrolytes) [1-3].

Combinations of these directions were used in this work. In particular, various ultrafine additives were introduced into the colloid electrolytes, thus additionally alloying the deposits with metals and/or non-metals. This makes it possible to obtain new composite electrochemical coatings (CEC) with special exploitative properties and various functional purposes, which contributes to solving environmental issues, cost-effectiveness and manufacturability of processes for their preparation at the same time.

The aim of this work was to research the effect of various nano-dispersed additives from electrolytes-colloid baths of formation of CEC on the base nickel having optimal physical

${ }^{*}$ Corresponding author: degtyar@yandex.ru 
and mechanical parameters.

The purpose of nano-dispersed materials is to give the CEC valuable properties that are not characteristic of the initial coating. Their influence on the metal can be different. However, an indispensable condition for their use is the formation of compositions with improved physical and mechanical or chemical properties that exceed the properties of initial components and the deposit as a whole.

Dispersed materials of both natural and synthetic origin can be used to obtain CEDs. Abrasive micropowders of serial production, some metal powders and a number of other materials are also widely used in the formation of compositions [4-8].

Dispersed additions penetrated into the electrochemically deposited metal or contacted with its surface violate the crystallographic structure and form defects (dislocations) in the crystal lattice. That is why the presence of dispersed materials in the electrolyte and their contact with the cathode even without inclusion in the deposit lead to hardening of the metal due to the fact that they violate the correct sequence of alternation of atomic planes [9]. Strengthening effect of dispersed particles in the electrolyte in suspension is manifested both at the time of capture (overgrowth) of the metal and at when it hits the surface of the cathode. At the moment of impact a particler shields the cathode by the contact with its surface, thereby distorting (complicating) the structure of the initial electrocrystallization of the metal. At the same moment nano-particler loses kinetic energy completely or partially: its energy depends on speed and the contact angle with the cathode. This process leads to the effect of adhesion hardening or grinding-polishing (cutting off microprotrusions of the surface). In this case, the structure of the deposit becomes more complicated and hardens as in the case of "capture" of nano-particler by the metal. The degree of hardening of the metal depends on the number of contacts of the nano-particlers with the cathode, their size, density and speed. The greater the concentration of nano-particlers in the electrolyte, the higher the strength of the resulting deposit $[10,11]$.

So, the CEC hardness is determined by the conditions of crystallization of the metal, the content and properties of dispersed additions, the conditions of electrolysis, and in most cases it has higher values than "pure" metals [12-13]. In particular, in the work [14] the hardness of the research deposit depends on the state of the intergranular boundaries between the grains of the dispersed phase and the metal matrix. And in the work [15] the finer grain and uniform distribution of the titanium nitride in alloy matrix favour the enhanced microhardness and corrosion resistance of the nanocomposite Ni-W-TiN.

As a result of literature analysis, nickel was chosen as the matrix metal and ultrafine additives: nanostructured zirconium diboride powder $(\mathrm{ZrB} 2$, ultrafine silicon carbide $(\mathrm{SiC})$ and ultrafine diamond (UDD). For scientific research, a colloidal electrolyte of the following composition (g/1) was used: nickel chloride hexahydrate 200, boric acid 30, ammonium sulfate 20, chloramine $\mathrm{B} 2.0, \mathrm{pH} 1-3$ [1]. The concentration of dispersed additives: the following, g / 1: ZrB2 5-60; SiC 5-100; UDD 0.05- 1.25. The agitation of the electrolyte was carried out using magnetic stirrer.

\section{Materials and Methods}

Electrolytes were prepared in distilled water using reagents from «Aldrich». To determine the content of additives in the deposit the weight (gravimetric) method was used. The microhardness of the CEC was determined using a PMT-3 microhardness meter on samples with a layer thickness of $30 \mu \mathrm{m}$ with a load of $100 \mathrm{~g}$ on the indenter. The measurement of current efficiency (CE) of nickel-based CEC was determined by coulometric method. A constant value of the potential was maintained by using the potentiostat "Elins P-8nano". To determine the internal tensiones (IT) in the deposit the flexible cathode method was used. 


\section{Results and discussion}

It seemed appropriate to start researching the effect of various additives on the formation of a composite electrolytic deposit from researches of the current efficiency in the declared electrolyte and in the presence of the declared additives in it (Figure 1). It is known [1] that current efficiency dependences in colloid electrolytes usually have an anomalous form. An excess of the current efficiency of nickel is a distinctive feature of electrolytes-colloid bathes, especially at low current densities, when the polarization does not reach the required value for the complete recovery of polydisperse particles of colloids and thin suspensions of the metal being restored at the cathode. At the same time, it is possible to obtain highquality galvanic deposits [2]. In our case such anomalous current efficiency values above $100 \%$ are observed in an electrolyte containing UDD (curve 4). However, in solutions containing additives $\mathrm{ZrB} 2$ and $\mathrm{SiC}$ (curves 1,2) the obtained form of dependence (parabolic) is characteristic of colloid electrolytes, but the current efficiency does not reach characteristic values. Almost rectilinear dependence is observed (curve 3) in an electrolyte without additives. Thus, optimal conditions are created for the inclusion of nanoparticles and the formation of the colloidal phase of nickel compounds in the electrolyte with the addition of UDD.

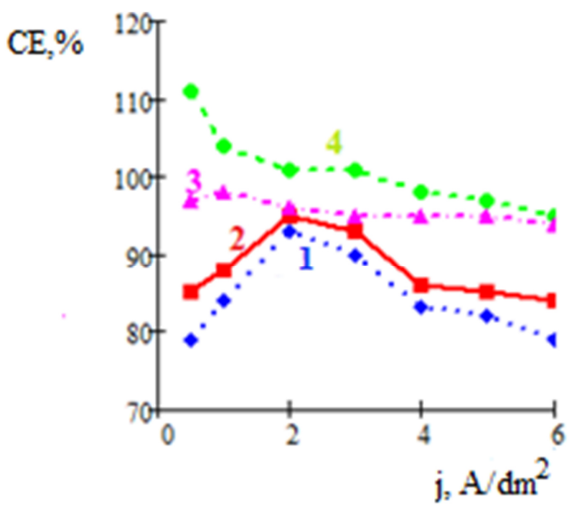

Fig. 1. The dependence of the current efficiency of nickel on the current density in the studied electrolyte ( $\mathrm{pH} 3$ ) with the following concentrations of additives, $\mathrm{g} / 1: 1-\mathrm{SiC} 30 ; 2-\mathrm{ZrB}_{2} 30 ; 3-0$; 4 - UDD 1.

The search of the optimal concentrations of the ultrafine additives was carried out by content of addition in the deposit (Figure 2), microhardness values (Figure 3) and internal tensions (Figure 4).
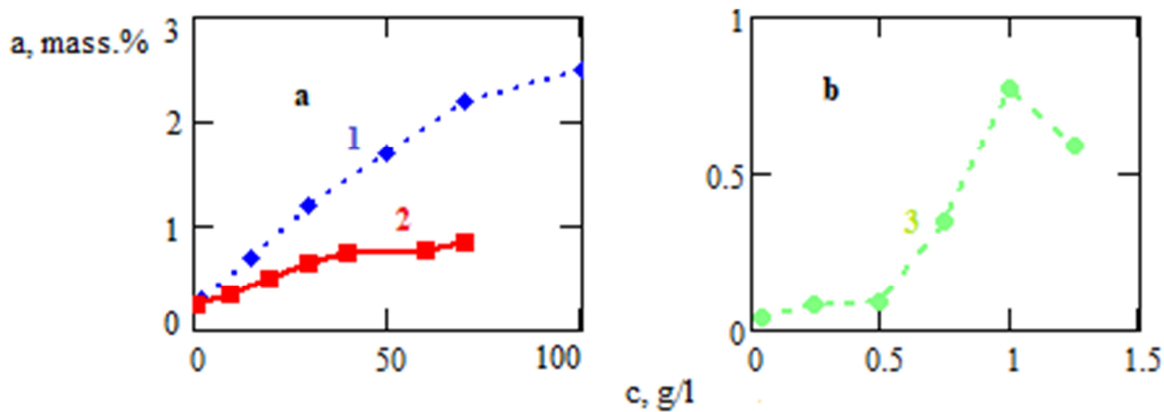

Fig. 2. The dependence of the content of ultrafine additives in CEC on the concentration of additives in the studied electrolyte at a cathodic current density of $3 \mathrm{~A} / \mathrm{dm}^{2}$ and $\mathrm{pH} 3 . \mathrm{a}: 1-\mathrm{SiC} ; 2-\mathrm{ZrB}_{2} ;$ b: 3 - UDD. 
It is shown (Figure 2a) that with an increase of the $\mathrm{SiC}$ concentration in the electrolyte its maximum content in the CEC is observed, with an increase of the $\mathrm{ZrB}_{2}$ concentration in the electrolyte its inclusion in the CEC increases slightly. A similar research of the dependence of the concentration of UDD in the electrolyte on its content in the composite deposit showed a maximum at a concentration of $1 \mathrm{~g} / \mathrm{l}$ of UDD.
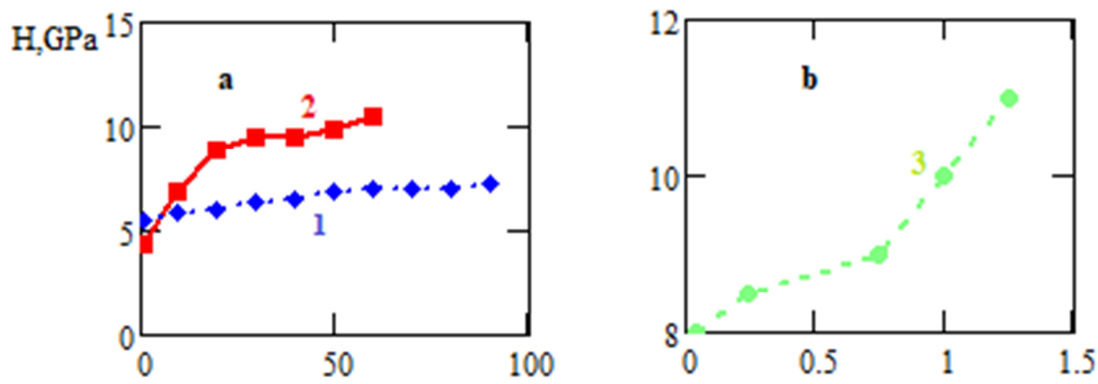

$$
c, g / 1
$$

Fig. 3. The dependence of the microhardness $(\mathrm{H})$ of CEC on the concentration of ultrafine additives in the studied electrolyte at cathodic current density of $3 \mathrm{~A} / \mathrm{dm}^{2}$ and pH 3. a: $1-\mathrm{SiC} ; 2-\mathrm{ZrB}_{2} ;$ b: 3 - UDD.

CEC with stable microhardness characteristics are formed at 30-40 g/l of SiC and ZrB2 (Figure 3a). However, hardness of deposits with the addition of $\mathrm{ZrB} 2$ are almost twice harder than those with the addition of $\mathrm{SiC}$. The maximum hardness values were obtained for CEC nickel-UDD (Figure 3b). The effect of increasing the microhardness of CEC in the presence of ultrafine additives is associated not only with the inclusion of solid particles in the deposit, but also with a decrease in crystalline grain at sufficiently high current densities. There is an opinion [16] that the presence of nanoparticles in the deposit contributes to the phenomenon of dispersion hardening of the nickel matrix. Moreover, in this case it is impossible to exclude the influence of finely dispersed nickel compounds formed in the colloidal electrolyte during its preparation or during electrolysis. The obtained microhardnesses of the CEC of $\mathrm{Ni}-\mathrm{ZrB}_{2}$ and Ni-UDD reach $10-11 \mathrm{GPa}$, that are four times higher than the microhardness of pure nickel and corresponds to the hardness of the chromium deposit.
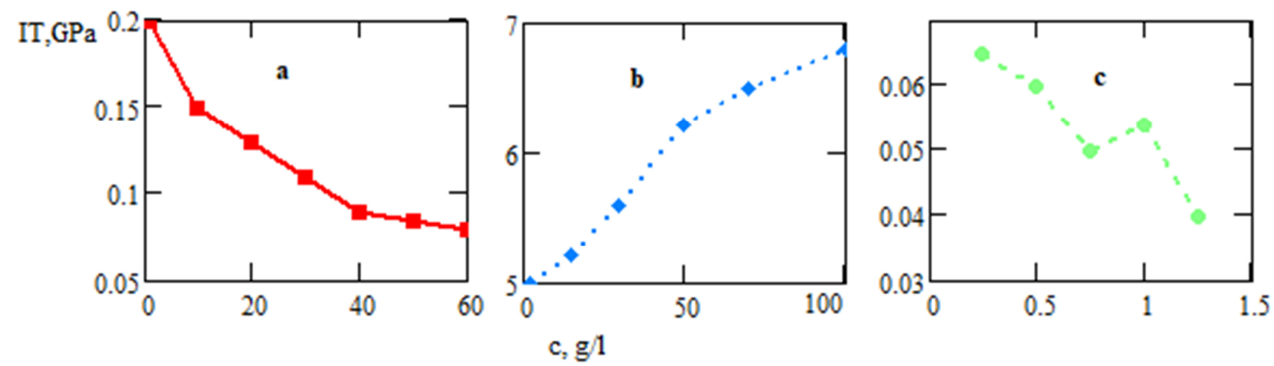

Fig. 4. Dependence of IT in CEC on the content of ultrafine additives in the studied electrolyte at cathodic current density of $3 \mathrm{~A} / \mathrm{dm}^{2}$ and $\mathrm{pH} 3: \mathrm{a}-\mathrm{ZrB}_{2} ; \mathrm{b}-\mathrm{SiC} ; \mathrm{c}-\mathrm{UDD}$.

IT researches shew that tensiones of compressive appear in deposits. Additives of $\mathrm{ZrB}_{2}$ and UDD reduce the IT of precipitation with an increase in their concentration in the electrolyte (Figure $4 \mathrm{a}, \mathrm{c}$ ). CEC nickel-UDD have minimal values of this indicator. On the other case effect of SiC is opposite cause. IT are increased with increasing concentration of $\mathrm{SiC}$ in the electrolyte.

Thus, high concentration of additives (above $40 \mathrm{~g} / \mathrm{l}$ ) of $\mathrm{ZrB}_{2}$ and $\mathrm{SiC}$ is impractical for 
economic and technological reasons, because the deposit is "saturated" by nano-additiones, and it is more difficult to solve the problem of efficient agitation. As a result of this the phenomenon of nano-particulares sticking on the surface of the samples is possible as well as the deterioration of the deposit quality.

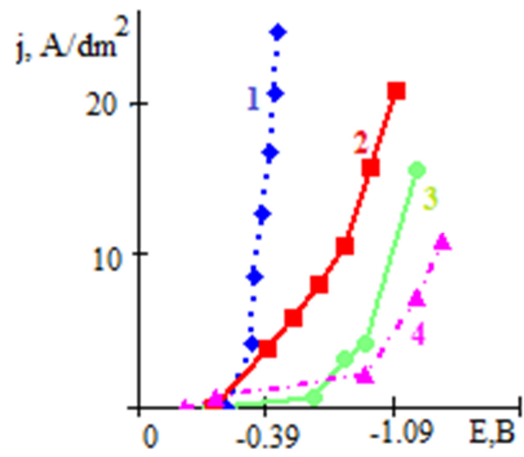

Fig. 5. Cathodic potentiostatic dependences in the studied electrolyte $(\mathrm{pH} 3)$ with the following concentrations of additives, $\mathrm{g} / \mathrm{l}: 1-\mathrm{SiC} 30 ; 2-\mathrm{ZrB}_{2} 30 ; 3-0 ; 4-\mathrm{UDD} 1$.

Potentiostatic researches shew that in a colloidal electrolyte without an additive (curve 3 ) in operating range a limiting current is observed. In our opinion, nickel compounds can be recovered at the cathode. It should be noted that the nickel current efficiency under these conditions is close to $100 \%$. When UDD and $\mathrm{ZrB}_{2}$ are introduced into the solution, it can be assumed that additional mechanical activation causes coagulation of some colloidal particles of nickel hydroxide. An conglomeration of dispersed compounds of nickel hydroxides occurs, that explains the appearance of limiting currents for their reduction (curves 2.4). Moreover, the limiting current has a higher value in an electrolyte with $\mathrm{ZrB}_{2}$ due to the higher concentration of the introduced ultrafine nano-addition. There are no limiting currents in the electrolyte with the addition of SiC. In our opinion, the mechanical activation of finely dispersed nickel compounds does not occur due to the other nature of the ultrafine additive. However, in this case there is a maximum decrease in polarization and an increase in electrolyte performance. Apparently, it is possible for the composite additive to participate in additional agitation of the hard-to-mix part of the diffusion layer together with colloidal nickel compounds.

\section{Conclusions}

This way, researches of the effect of various nano-additives for electrochemical colloidelectrolyte nickel plating of shew that the most effective nanostructured additives are zirconium diboride and ultrafine diamond. Current efficiency and potentiostatic researches shew mutual participation of finely dispersed nickel hydroxide compounds in the formation of a CEC and dispersed phase of zirconium diboride or ultrafine diamond that are attendant in the solution or formed during electrolysis and introduced into the electrolyte. It was established that low internal tensiones $(0.05-0.1 \mathrm{GPa})$ and increased microhardness values of 10-11 GPa are associated with the hardening of the nickel matrix together with nanodispersed additives of various nature included in the galvanic precipitation.

\section{References}

1. L. Degtyar, I. Zhukova, V. Mishurov, Materials Science Forum 945, 682-687 (2019) doi: 10.4028/www.scientific.net/MSF.945.682 
2. H. Afsar Lajevardi, T. Shahlavi, J.A. Szpunar, The Electrochemical Society 6, 275 281 (2017) doi:10.1149/2.0731706jes

3. V. Balakai, A. Arzumanova, K. Balakai, Russian Journal of Applied Chemistry 1, 65 71 (2010) doi: 10.1134/S1070427210010143

4. Ching An Huang, Shu Wei Yang, Chia Hsuan Shen, Kuang Chun Cheng, Hai Wang, Po Liang Lai, The International Journal of Advanced Manufacturing Technology 104, 2981-2989 (2019) doi:10.1007/s00170-019-04174-3

5. Na Li, Lan Zhang, Yongchao Zhu, Miting Xu, Yuxi Xu, Xinwei Ruan, Huizhong Ma, Journal of The Electrochemical Society 5, 215 - 222 (2018) doi: 10.1149/2.1061805jes

6. J.R. L'opez, P. M'endez, J. Perez Bueno, G. Trejo, G. Stremsdoerfer, Y. Meas, The Electrochemical Society 14, 753 - 760 (2018) doi:10.1149/2.1111814jes

7. E. Molodkina, Y. Polukarov, A. Danilov, J. Souza-Garcia, J. Feliu, Electrochimica Acta 1, 154-165 (2010) doi:10.1016/j.electacta.2010.08.105

8. A. Igual Muñoz, N. Alonso-Morales, J. Palomar, M.A. Gilarranz, S. Mischler, Journal of The Electrochemical Society 6, 181-188 (2019) doi:10.1149/2.0321906jes

9. Y. Kisel, G. Guryanov, IOP Conf. Ser.: Mater. Sci. Eng. 3, 032047 (2018) doi: $10.1088 / 1757-899 X / 450 / 3 / 032047$

10. A. Davydov, V. Volgin, Russian Journal of Electrochemistry 9, 806-831 (2016) doi: $10.1134 / \mathrm{S} 1023193516090020$

11. L. Isern, S. Impey, J. Clouser, D. Milosevic, J. Luis Endrino 165, 402-410 (2018) doi: 10.1149/2.1161809jes

12. K. Alipour, F. Nasirpouri, The Electrochemical Society 166, 1-9 (2019) doi: 10.1149/2.0191902jes

13. H. Zhou, N. Du, L. Zhu, J. Shang, Z. Qian, X. Shen, Electrochimica Acta 151, 157-167 (2015) doi.org/10.1016/j.electacta.2014.10.122

14. J. Giallonardo, U. Erb, K.T. Aust, G. Palumbo, Philosofical Magazine 91, 4594-4605 (2011) doi:10.1080/14786435.2011.615350

15. K. Arunsunai Kumar, G. Paruthimal Kalaignan, V.S. Muralidharan, Transactions of the Institute of Metal Finishing 91, 202-206 (2013) doi: 10.1179/0020296713Z.000000000110

16. A. Martínez-Hernández, F. Manríquez-Guerrero, J. Torres and others, Electrodeposition of Composite Materials, 130-143 (2016) doi:10.5772/61858 